\title{
House Price Shocks, Stock Returns, and Policy Uncertainty: An Empirical Analysis Based on SVAR Models
}

\author{
Yi-Xuan LIN ${ }^{\mathrm{a},{ }^{*}}$, Xuan WEl ${ }^{\mathrm{b}}$ and Chi-Chuan LEE ${ }^{\mathrm{c}}$ \\ School of Management, Beijing Normal University Zhuhai, Zhuhai, China \\ aflorenceeelin@126.com, bwhitneywei1996@163.com, 'leechichuan@bnuz.edu.cn \\ ${ }^{*}$ Corresponding author
}

Keywords: House price, Stock price, Economic policy uncertainty, SVAR model.

\begin{abstract}
This paper investigates the dynamic relationship among house price shocks, stock returns, and economic policy uncertainty (EPU) using a Structural VAR framework for a data sample of China over the period 1997-2016. The conclusions drawn are as follows. (1) An increase in EPU decreases house prices. A rise in house prices decreases EPU, while a rise in house supply increases EPU. (2) An increase in EPU decreases stock prices in the short term, while a rise in stock prices decreases EPU. (3) The interaction between stock prices and house prices is statistically insignificant. On the basis of the findings, relevant suggestions are put forward.
\end{abstract}

\section{Introduction}

A well-functioning capital market is important not only to finance growth but also to provide economic stability. It is well- recognized that housing market and stock market are two of the most popular investment places in China. As an important capital market, the real estate sector is an essential part of any country's economic growth. Today, with the development of urbanization and improvement of people's living standards, demand for housing continues to increase. As another important capital market, the stock market is a place where both investors and speculators come together to actively participate. Stock prices are determined by many factors, such as the economy, politics, investors' preferences, and trade technology. Therefore, stock investors are very sensitive to economic policies and also pay great attention to house prices.

With the emergence of the 2008 global financial crisis, increasing economic policy uncertainty (EPU) has had a serious influence on both real estate and stock markets. On the other hand, house and stock price fluctuations also influence economic policies, as authorities look to stabilize their economy and avoid any adverse economic phenomenon like a housing bubble. In short, it is critical to find the linkages among housing prices, stock prices, and economic policy uncertainty. Figuring out the interactions and reciprocal influences of those three things can help people and authorities understand the factors affecting asset price swings and market uncertainty risks. Governments should supervise the markets and ensure that the economic system undergoes stable development.

Previous researches mainly focus on the relationship between house price and stock price. Liang and Naranjo [1] point out that these two variables have a co-integration relationship. Clayton [2] holds the opinion that changes in the real estate market have a huge impact on the stock market. For the relationship between asset prices and economic policies, Genberg [3] believes that asset price fluctuations influence financial stability and macroeconomic stability. Most researchers focus on the interactions between only two of the three variables (house price, stock and EPU). Research on the three variables together has not yet been carried out. The majority of researchers pick monetary policy as a reference factor that effects macroeconomic fluctuations, while not taking EPU into account. Moreover, most papers only consider house price changes and do not distinguish the effects of housing supply and demand. Hence, this paper analyzes house prices' impact on China's macro-economy from two perspectives (housing supply and demand), demonstrates a more comprehensive analysis of the relationships among house price, stock price, and EPU and provides decision-making advice for investors, enterprises, and the government. 


\section{Theoretical Structure and Empirical Model}

The VAR model is a non-structural model that uses a simultaneous equation association and conducts a regression on endogenous variables. We model the joint dynamics of stock price, house price, and EPU by means of the following VAR model:

$$
\begin{gathered}
y_{t}=c+\sum_{i=1}^{p} A_{i} y_{t-1}+\mu_{t} \\
\mathrm{E}\left(\mu_{t}, \mu_{t}^{\prime}\right)=\Omega
\end{gathered}
$$

In this model, $y_{t}=(\mathrm{HSS}, \mathrm{HDS}, \mathrm{STOCK}, \mathrm{EPU})$ is a $4 \mathrm{x} 1$ vector of endogenous variables, $\mathrm{c}$ represents the vector of constant terms, $A_{i}$ refers to the $\mathrm{n} x \mathrm{n}$ auto-regressive coefficient matrix (a parameter matrix of all hysteresis variables), and $\mu_{t}$ stands for the simplified residual column vector. Since the VAR model tends to focus on hysteresis structures and relationships among variables, it does not clearly show the structural relationships among all data, and thus structural correlations among variables will be hidden. Simplified residuals of the VAR model are the sum of the SVAR model's residuals. The SVAR model includes relationships of variables at a corresponding period, making up for the deficiency of the VAR model. Therefore, this paper establishes the SVAR model as follows:

$$
\mathrm{B}_{0} \circ y_{t}=d+\sum_{i=1}^{p} \Gamma_{i} y_{t-1}+\varepsilon_{t}
$$

The model presented as lag operators is as follows:

$$
\mathrm{B}(\mathrm{L}) \circ y_{t}=k+\varepsilon_{t}, \mathrm{E}\left(\mu_{t}, \mu_{t}^{\prime}\right)=\mathrm{I}
$$

In this model, $\mathrm{k}$ represents the deterministic trend term after transformation, which is the polynomial matrix of lagging operating order. It denotes the structural residual vector and includes information of unrelated structural shocks. Its variance is a unit matrix.

According to the identification condition of the SVAR model [4], we make four hypotheses as follows. (1) Current house sales area is not affected by other variables. (2) Current house price is not affected by other variables except for house sales area. (3) Current stock price is only affected by house sales area and house price. (4) Current EPU is not affected by all other variables. Therefore, the impulse relationships among the data are as follows:

$$
\left(\begin{array}{cccc}
1 & 0 & \cdots & 0 \\
-b_{21} & 1 & \vdots & 0 \\
\vdots & \vdots & \ddots & \vdots \\
-b_{41} & -b_{42} & \cdots & 1
\end{array}\right) \circ\left(\begin{array}{l}
\mu_{H S S} \\
\mu_{H D S} \\
\mu_{S T O C K} \\
\mu_{E P U}
\end{array}\right)=\left(\begin{array}{l}
\varepsilon_{H S S} \\
\varepsilon_{H D S} \\
\varepsilon_{S T O C K} \\
\varepsilon_{E P U}
\end{array}\right)
$$

\section{Data Description}

This paper selects commercial residential buildings in China as the research subject, which represents the supply-side factor that affects house price fluctuations. The data are collected from CEInet statistics database. In order to effectively measure price changes in the stock market, we use the return of the Shanghai Composite Index(SCI) as a reference to measure the stock price. To proxy for policy uncertainty, we collect EPU index data constructed by Baker et al. [5] from the economic policy uncertainty website (http://www.policyuncertainty.com)Since statistics of EPU only started being collected from 1995, the time span of all variables in the paper is from 1997 to 2016.

\section{Empirical Results}

First, we carry out a descriptive statistical analysis of each variable and present the historic trends of all variables in the form of graphs. Second, we assess the stability properties of the data by means of a unit root test, in order to guarantee the validity of this model. Table 1 presents descriptive statistics and the results of unit root tests. This paper employs the ADF test and KPSS test to examine the original sequences and first difference sequences of all variables. 
Table 1 Descriptive statistics and unit root tests

\begin{tabular}{ccccccc}
\hline Variable & Mean & Std. Dev. & Max. & Min. & ADF & KPSS \\
\hline HSS & 6126.29 & 5062.83 & 21807.84 & 274.31 & -1.19 & $0.53^{* * * *}$ \\
HDS & 3218.05 & 3362.32 & 15124.35 & 35.02 & -1.32 & $0.47 * * *$ \\
STOCK & 0.0083 & 0.0809 & 0.3206 & -0.2463 & $-13.42^{* * *}$ & 0.03 \\
EPU & 126.79 & 90.86 & 646.91 & 9.07 & $-4.72^{* * *}$ & 0.07 \\
\hline
\end{tabular}

Note: ***,**, and * indicate statistical significance at the $1 \%, 5 \%$, and $10 \%$ levels, respectively.

As for the stationarity test, except stock return, we convert the series into natural logarithmic form before analysis. Table 1 reports that both HDS and HSS fail to reject the unit root null from the ADF test and reject the stationary null from KPSS test in levels. This means that both house demand and supply shocks are not stationary. As to the other variables, evidence shows that both STOCK and EPU are stationary. Based on the findings above, we adopt stock price and EPU in levels, as well as HDS and HSS in first differences, for further analysis of the SVAR model.

Before proceeding to the SVAR model, it is important to choose an appropriate lag length to provide an accurate estimation. This paper employs the Likelihood Ratio, Final Prediction Error, Akaike Information Criterion, Schwarz Information Criterion, and Hannan-Quinn Information Criterion to select the optimal lag length. The results indicate that the optimal lag length of this VAR model can be set to five ( The results are not shown to save space, but available upon request from the authors.). We next carry out impulse response functions to test the intensity of reciprocal influences and their duration time of EPU, sales area, sales amount, and stock return. Figs 1-10 present the results.

Figs 1-2 report reciprocal influences of EPU and demand for commercial residential buildings (house sales amount). Results show that a positive shock of EPU significantly decreases the demand. This influence reaches significance at the fifth period, implying that an increase in EPU aggravates house demand fluctuation, leading to a fall in house prices. On the other hand, a positive shock of house demand (house price) also significantly decreases EPU. This implies that an increase in house prices decreases EPU.

Figs 3-4 report reciprocal influences of EPU and supply of commercial residential buildings (house sales area). Results show that a positive shock of EPU significantly decreases house sales area. This response is practically consistent with that of house sales amount to EPU, implying that an increase in EPU aggravates a negative fluctuation of house supply. On the other hand, a positive shock of house supply (house sales area) generally increases EPU. This implies that an increase in house supply increases EPU.

In short, economic policy uncertainty decreases both house supply and demand, thus contributing to lower house prices in China. In light of this phenomenon, one interpretation is that a high level of EPU delays individual consumption and investment of houses as well as the house supply provided by real estate enterprises. This can lead to potential market failure, causing house

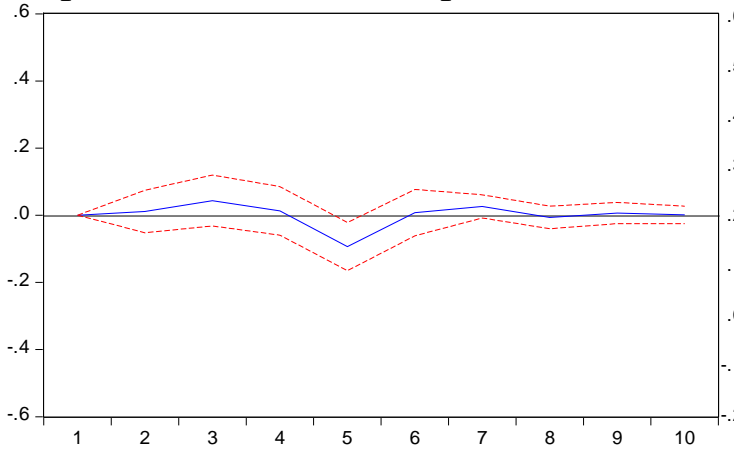

Fig. 1 IRF of sales amount to EPU

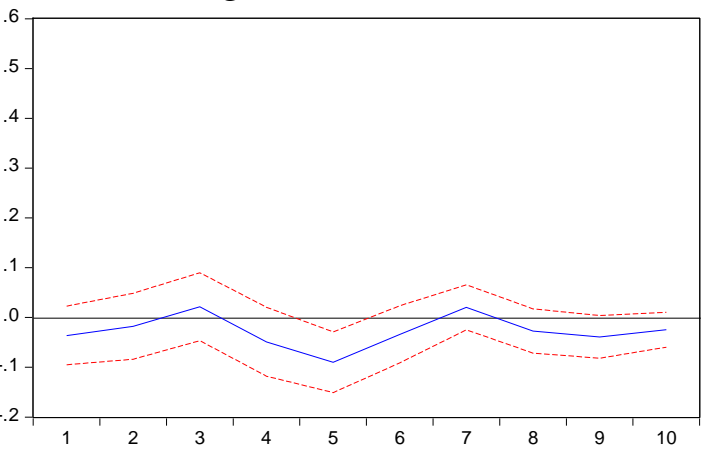

Fig. 2 IRF of EPU to sales amount 


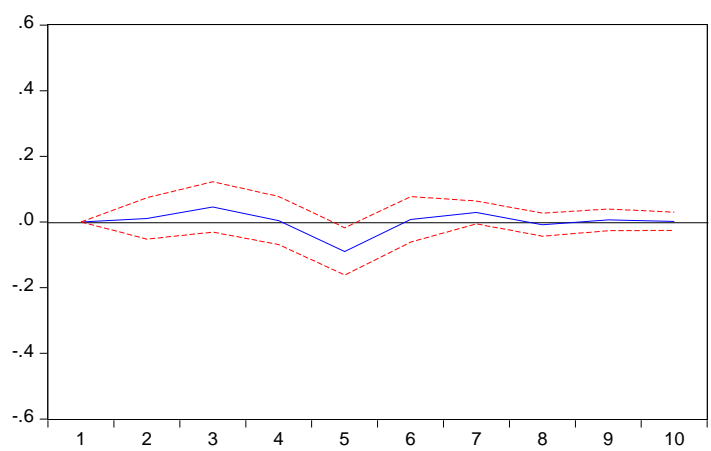

Fig. 3 IRF of sales area to EPU

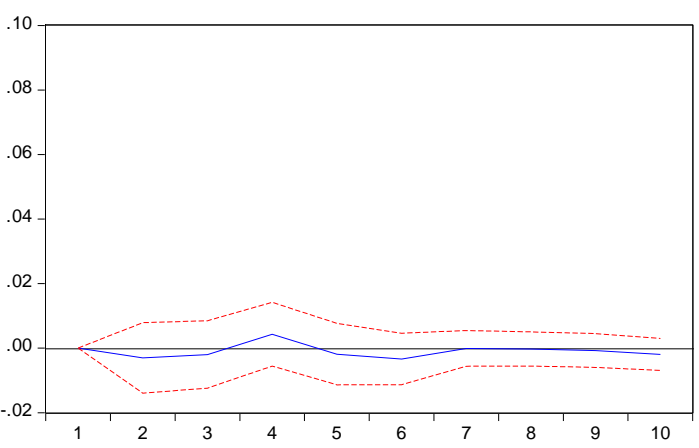

Fig. 5 IRF of stock price to EPU

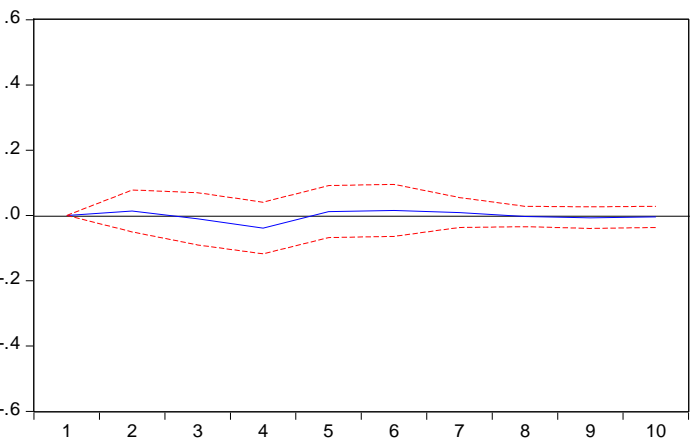

Fig. 7 IRF of sales area to stock price

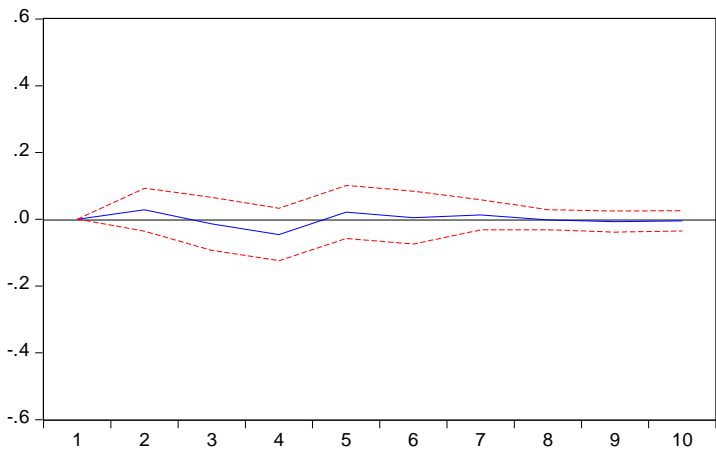

Fig. 9 IRF of sales amount to stock price

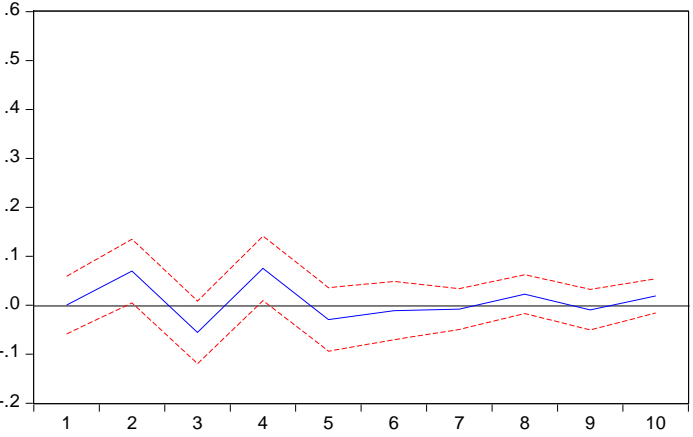

Fig. 4 IRF of EPU to sales area

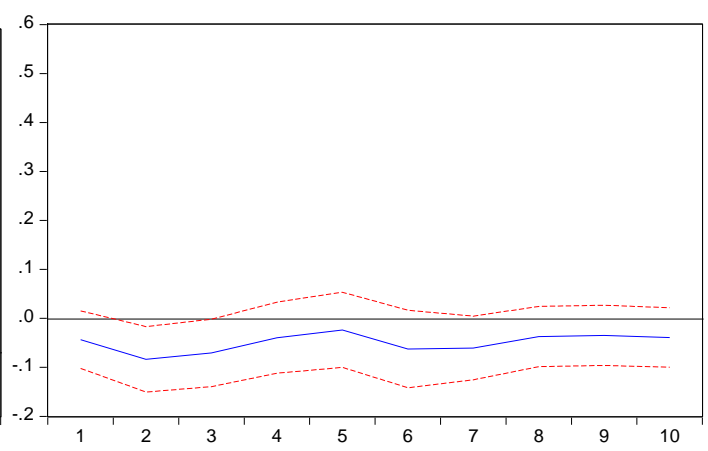

Fig. 6 IRF of EPU to stock price

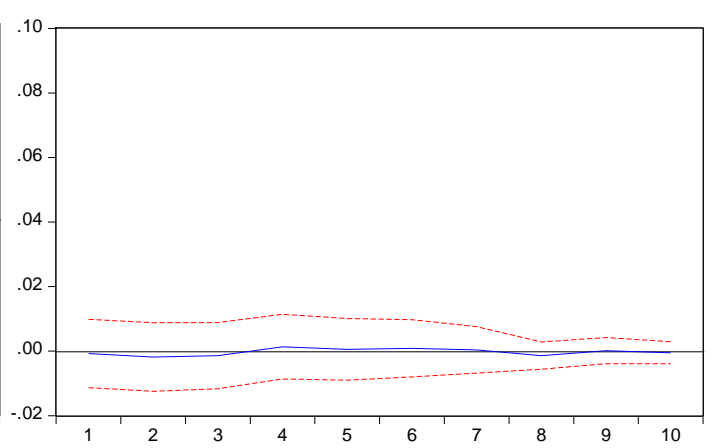

Fig. 8 IRF of stock price to sales area

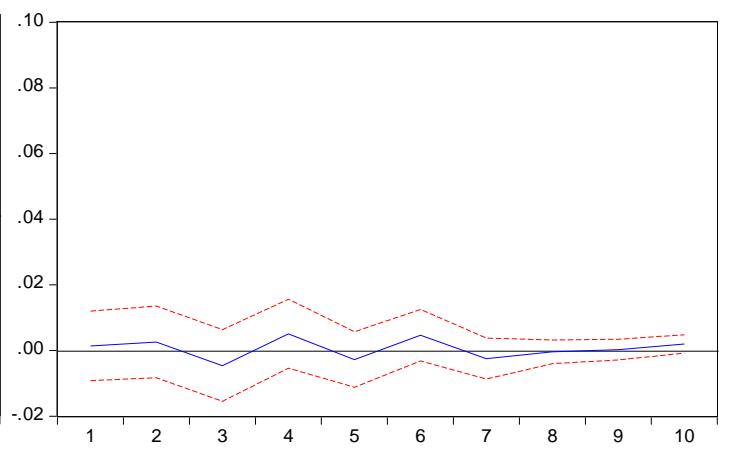

Fig. 10 IRF of stock price to sales amount

prices to fluctuate meaninglessly. In addition, an increase in house demand decreases EPU, while an increase in house supply increases EPU. One possible explanation for this is that an increase in house demand motivates the government to put forward steady development policies for the real estate market, such as property-purchasing limitations. House supply, however, is harder to control.

Figs 5-6 report reciprocal influences of EPU and the rate of return of SCI. Results show that a positive shock of EPU insignificantly decreases stock prices. This implies that an increase in EPU decreases stock prices in the short term. One explanation is that investors in China tend to be irrational and speculative. 
Therefore, over-reaction to short-term effects of policies and under-reaction to their long-term effects lead to EPU only having a short-term overflow effect. On the other hand, a positive shock from the rate of return of SCI significantly decreases EPU. This implies that an increase in stock prices decreases EPU. When stock prices are high, oftentimes it means the macro-economy is good and economic policies are relatively steady.

Figs 7-8 present reciprocal influences of house sales area and EPU. Results show that a positive shock of EPU slightly decreases house sales area at the fourth period, implying that at that time an increase in EPU will decrease house prices on a small scale, but the fluctuation is insignificant before and after that. This can be accounted for as follows. When EPU reaches a certain level, the determination of real estate developers is likely to be shaken, and therefore house supply will decrease. On the other hand, the impulse response of the rate of return of SCI to house sales area is not statistically significant, meaning that house supply barely affects stock prices.

Figs 9-10 illustrate reciprocal influences of house sales amount and stock prices. Results show that a positive shock of stock prices unstably influences house sales amount, sometimes upward and sometimes downward. This implies that whether the stock market and real estate market are complementary or substitutional is still not clear. On the other hand, the response of stock price to house sales amount is also unstable. Fluctuations are both positive and negative, but fluctuations in both directions are not statistically significant. This implies that house demand has a negligible impact on stock price.

In short, the mutual influences of stock price and house price are overall insignificant. One interpretation for this is the wealth effect [6]. At first, a stock market boom offers constant cheap funding for the real estate market. However, as time goes by, the real estate market gradually comes to a saturation state, where house supply and demand will not change much even though stock prices continue to rise. Lastly, variance decomposition of all variables are conducted(The results are not shown to save space, but available upon request from the authors.). This process demonstrates how structural shocks affect endogenous variables of the model. The forecasting error variance ratio reflects the contribution value, and thus the results of reciprocal influences of all data are given more intuitively.

According to the results, the impact of EPU on house supply is smaller than that of stock price over the first three periods. However, since the fourth period, the impact of EPU precedes the impact of stock price. From the fifth period onward, the impact of EPU starts reaching higher than $2.85 \%$ and keeps this level afterwards. Though the impact of stock price is relatively small, it starts maintaining a level above $0.5 \%$ starting from the fourth period. As to the variance decomposition of house demand, EPU has a larger impact on house demand. This impact reaches $3 \%$ since the fifth period, while the impact of stock price only reaches $1 \%$ for two periods.

For stock price, house demand affects stock price the most. It gradually increases and precedes $1 \%$ since the sixth period. The impact of EPU is the second biggest. It precedes $0.5 \%$ since the fifth period and gradually increases afterwards. The impact of house supply is relatively small, yet it gradually increases over time. As far as the variance decomposition of EPU are concerned, the impact of stock price on EPU is the most significant. It precedes $3 \%$ at the second period, and its highest point is $6.41 \%$. Although over the last two periods the impact of demand is slightly bigger than that of supply by $0.3 \%$, the overall house supply affects EPU more greatly than house demand. This impact reaches its peak at $4.56 \%$ at the fourth period. The peak of impact from house demand is only $3.95 \%$.

\section{Conclusions and Suggestions}

This paper fills the gap in the literature on the reciprocal influences of EPU, house price, and stock price in China by analyzing house supply and demand, which both affect house price. The conclusions drawn are as follow. (1) An increase in EPU decreases house prices. A rise in house prices decreases EPU, while a rise in house supply increases EPU. (2) An increase in EPU decreases stock prices in the short term, while a rise in stock prices decreases EPU. (3) The interaction between stock prices and house prices is statistically insignificant.

In order to reduce the negative effects of EPU to the stock market and real estate market, the China government should seek to execute steady economic policies under various circumstances. This is because simple and steady policies are able to avoid adding uncertainty to the whole economic 
environment, thus reducing negative effects to stock price and house price caused by EPU. The key to implementing steady economic policies is to moderately control the market, to put emphasis on coordination, and to look into the future. To be more detailed, the government should pay attention to five principles: deficit control, structure adjustment, reform promotion, revenue augmentation, and expenditure reduction. In face of EPU, it is more beneficial to investors in both markets to make optimal decisions when policies are more open and transparent.

The government should also take measures to prevent strong uprising trends of stock price and house price from happening by, for example, stopping irrational investment behaviors. Effective interaction between the stock market and real estate market should be encouraged and supported by the relevant authorities. New individual investors generally lack systematic knowledge of securities and real estate and an awareness of risk. These investors have a lower level of risk-taking ability and have little capacity for self-protection. To prevent this kind of investors from being misled about rising stock prices, they should be educated about investment risk. This requires not only participation by the government, but also from securities firms' supervisory department, securities traders, schools, and intermediary organizations.

\section{Acknowledgement}

This research was financially supported by the Students Platform for Innovation and Entrepreneurship Training Program. (Grant Number: 201713177020).

\section{References}

[1] D. Naranjo, D.C. Ling, Economic risk factors and commercial real estate returns, J. Real Estate Financ. Econ. 14 (1997) 283-307.

[2] J. Clayton, N. Miller, L. Peng, Price-volume correlation in the housing market: Causality and co-movements, J. Real Estate Financ. Econ. 40 (2010) 14-40.

[3] H, Genberg, Asset prices monetary policy and macroeconomic stability, De. Econ. 149 (2001) 433-453.

[4] L. Kilian, Not all oil price shocks are alike: disentangling demand and supply shocks in the crude oil market, Am. Econ. Rev. 99 (2009) 1053-1069.

[5] S.R. Baker, N. Bloom, S.J. Davis, Measuring economic policy uncertainty, Quart. J. Econ. 131 (2016) 1593-1636.

[6] G. Haberler, Prosperity and depression, J. Polit. Econ. 49 (1941) 289-291. 